\title{
Utilization of Egg Albumen: Application and Optimization of Gelatin and Carrageenan for Pudding Production via Response Surface Methodology (RSM)
}

\author{
Sunee Eadmusik ${ }^{1, *}$, Daungporn Chaiya ${ }^{1}$, and Supaporn Soichuen ${ }^{1}$ \\ ${ }^{1}$ Department of Agro-industry Technology and Management, Faculty of Agro-industry, King Mongkut's University of Technology \\ North Bangkok, Prachinburi, Thailand
}

\begin{abstract}
This study was aimed to develop an albumen pudding by application and optimization of gelatin and carrageenan as food additives using response surface methodology (RSM). Albumen pudding was produced from $55 \%(\mathrm{v} / \mathrm{v})$ albumen concentration. Effect of concentrations of gelatin $(2,4$ and $6 \%$ $(\mathrm{w} / \mathrm{v}))$ and carrageenan $(0.3,0.5$ and $0.7 \%(\mathrm{w} / \mathrm{v}))$ on pudding's physical and sensorial properties was investigated. Results revealed that a concentration of food additives correlated with syneresis, springiness, hardness, firmness and overall liking scores $\left(\mathrm{R}^{2}=0.932,0.821,0.956,0.854\right.$ and 0.864 , respectively). The higher gelatin and carrageenan concentrations added, the lower syneresis, springiness, hardness, firmness and overall liking scores were observed. The overall liking score ranged from 5.9-6.7 (slightly-liked to moderately-liked) compare to 7.5 (moderately-liked) of the control sample. From RSM analysis, the suitable concentrations of gelatin and carrageenan were $1.5-5.6 \%(\mathrm{w} / \mathrm{v})$ and $0.25-0.61 \%(\mathrm{w} / \mathrm{v})$, respectively.
\end{abstract}

\section{Introduction}

Traditionally, tofu (soybean curd) is made by protein coagulation of soymilk using a coagulant followed by moulding and pressing to draw the whey [1]. There are several tofu categories based on their firmness which varied from soft to firm with moisture content ranging from $70 \%$ to $90 \%$ [2]. Tofu pudding (soybean pudding) is one of the major tofu types. It has a soft texture and is often consumed as dessert. Several researches on tofu have been studied such as determination the role of incubation time and gelation rate in soymilk gelation process [3], development of calcium fortified tofu [4]. Effort to produce tofu-liked product from other protein source i.e. egg white is also taken [5].

Egg white, also called egg albumen, is a good source of protein and essential amino acids. It is common used in food industry due to its functional properties. Egg albumen owns two major functional properties which are foam forming and heat-induced gelling properties $[6,7]$. Recently, innovative products form egg albumen have been developed. Masure et al. [8] investigated an impact of egg white protein on gluten free bread structure. Gogo et al. [9] utilized egg albumen in a protein-rich yoghurt production.

Although egg albumen can form a gel when it is heated, a heat-induced albumen gel is hard and nonelastic. These undesirable textures limit a utilization of egg albumen in food development. The rheological and physicochemical properties of many processed and convenience foods involve with the behaviour of protein and polysaccharide components [1]. Polysaccharides play a key role in modifying the textural properties of protein food system so that they are used as food additive.

Carrageenan is widely used to improve food texture for its thickening, stabilizing and gelling properties. It is a group of sulphated linear polysaccharides of Dgalactose and 3,6 anhydro-D-galactose and capable of forming complexes with protein in the presence and absence of calcium ions due to its being negative charge polysaccharides over a wide range of $\mathrm{pH}$ [1]. Gelatin, other alternative food additive, is one of the most popular gelling agent. It is a denatured protein derived from collagen connective tissue of muscles, skin and bone of animal by thermo-hydrolysis. Gelatin is reported to improve syneresis of food $[10,11]$.

The response surface methodology (RSM) is a powerful technique for testing multiple process variables because fewer experimental trials are needed compared to the study of one variable at a time [12]. This present work is aimed to utilize egg albumen in pudding production and to implement RSM technique on the optimization of gelatin and carrageenan concentrations for egg albumen pudding production.

\section{Materials and methods}

\subsection{Egg albumen pudding preparation}

Albumen was separated from yolk of the broken whole egg and dissolved in water $55 \%(\mathrm{v} / \mathrm{v})$. Gelatin solutions at 2,4 and $6 \%(\mathrm{w} / \mathrm{v})$ were prepared separately by dissolve in boiling water while Carrageenan solutions at

\footnotetext{
* Corresponding author: sunee.e@agro.kmutnb.ac.th
} 
$0.3,0.5$ and $0.7 \%(\mathrm{w} / \mathrm{v})$ were dissolved in roomtemperature water. Then, various concentrations of gelatin and carrageenan were added into the previous prepared egg albumen. The solution was stirred and then heated at $90^{\circ} \mathrm{C}$ for 50 min using water bath. The albumen pudding was kept overnight in a refrigerator at $4{ }^{\circ} \mathrm{C}$ prior the determination of physical and sensorial properties.

\subsection{Proximate analysis of albumen}

The Official Methods of Analysis of AOAC International were used for the determination of moisture, crude fat and ash contents in albumen [13]. The protein content was determined by the Kjeldahl method with a nitrogen conversion factor of 6.25 . The carbohydrate content was calculated by subtraction from the other contents.

\subsection{Colour measurement}

The colour parameters $\left(L^{*}, a^{*}\right.$ and $\left.b^{*}\right)$ of a pudding sample were measured with a colorimeter (HunterLab colorFlex 4510, USA.) using illuminant $\mathrm{D}$ and $65^{\circ}$ standard observer. The colorimeter was calibrated using white and black standard reflective calibration plates. The total colour difference $\left(\Delta E^{*}\right)$ was calculated as following equation

$$
\Delta E^{*}=\sqrt{\left(L *_{0}-L *_{1}\right)^{2}+\left(a *_{0}-a *_{1}\right)^{2}+\left(b *_{0}-b *_{1}\right)^{2}}
$$

where $L *_{0}, a *_{0}$ and $b^{*_{0}}=$ the colour parameters of a commercial soybean pudding (control) and

$L *_{1}, a *_{1}$ and $b^{*}{ }_{1}=$ the colour parameters of a sample pudding

\subsection{Syneresis measurement}

Syneresis measurement was performed following the method of Amatayakul et al. [10] with some modification. Albumen pudding sample was cut into three pieces of $3 \times 3 \times 3 \mathrm{~cm}$ cube and weighed. They were drained on a sieve for 7 days at $4^{\circ} \mathrm{C}$. The weight of drainage was recorded at 1, 3, 5 and 7 day. The syneresis was expressed as the percent weight of the drainage separated from the pudding sample over the initial weight of the pudding sample.

\subsection{Texture Profile Analysis}

Texture profile analysis (TPA) of albumen pudding was performed using a TA-XT plus texture analyser (Stable Micro System Ltd, Godalming, UK). The $3 \times 3 \times 3 \mathrm{~cm}$ cube of albumen pudding was measured using a cylinder probe (36 $\mathrm{mm}$ diameter) with the penetration speed of 1 $\mathrm{mm} / \mathrm{s}$. Hardness $(\mathrm{g})$, springiness $(\mathrm{mm})$, cohesiveness and gumminess $(\mathrm{g})$ were quantified from the TPA curve.

\subsection{Sensory evaluation}

The sensory evaluation of albumen pudding was carried out by 40 panellists. All pudding samples were coded in 3-digit numbers and presented in a randomised arrangement. Tests on colour, springiness, hardness, firmness and overall liking were conducted a 9-point hedonic scale (1.00 to 1.89 - extremely dislike; 1.90 to 2.79-very much dislike; 2.80 to 3.69 -moderately dislike; 3.70 to 4.59 - slightly dislike; $4.60-5.49$ - neither like nor dislike; 5.50 to 6.59 - slightly like; 6.60 to $7.69-$ moderately like; 7.70 to 8.79 - very much like and 8.80 to 9.00 - extremely like).

\subsection{Statistical analysis}

Experiments were carried out in triplicate. The data were expressed as mean \pm standard deviation. The means of all parameters were examined using analysis of variance (One-way ANOVA). Duncan's New Multiple Range Test (DMRT) was used to determine the multiple comparison of mean values at a level of $\mathrm{P}<0.05$. A SPSS statistical program version 16 was used to carry out the calculation.

Response surface methodology (RSM) was used to proposed mathematical equation. Suggested model or predictive model for every response (Y) was with linear, quadratic and interactive components as following equation:

$$
\mathrm{Y}=\beta_{0}+\beta_{1} \mathrm{X}_{1}+\beta_{2} \mathrm{X}_{2}+\beta_{11} \mathrm{X}_{1}^{2}+\beta_{22} \mathrm{X}_{2}^{2}+\beta_{12} \mathrm{X}_{1} \mathrm{X}_{2}
$$

where $\mathrm{Y}$ is response, $\mathrm{X}_{1}$-gelatin concentration, $\mathrm{X}_{2}$ carrageenan concentration, $\beta_{0}$ - intercept, $\beta_{1}, \beta_{2}$ - linear, $\beta_{11}, \beta_{22}$ - quadratic and $\beta_{12}$ - interaction regression coefficient terms, respectively. The quality and adequacy of the model were measured by the regression coefficient $\left(\mathrm{R}^{2}\right)$ and the significance of the model. TIBCO Statistica v. 13 software (TIBCO Statistica, USA) was used for RSM and the optimization analyses.

\section{Results and discussion}

\subsection{Chemical composition of egg albumen}

Chicken egg albumen was composed of an abundant of moisture $(87.77 \%)$ and very low crude fat $(0.15 \%)$ (Table 1.) Contents of protein, carbohydrate and ash were $10.69,0.74$ and $0.68 \%$, respectively. Similar results were reported by Chaiyasit et al. [14] and Stadelman and Cotterill [15] who reported that moisture content of egg albumen was up to $89 \%$ and crude fat was less than $0.03 \%$.

Table 1. Proximate analysis of egg albumen.

\begin{tabular}{|l|c|c|c|}
\hline Composition & \multicolumn{3}{|c|}{ Content (\%) } \\
\hline Moisture & $87.77 \pm 0.01$ & $88.48 \pm 0.05$ & $87.87-89.37$ \\
\hline $\begin{array}{l}\text { Protein } \\
(\% \mathrm{~N} x \text { 6.25) }\end{array}$ & $10.69 \pm 0.01$ & $10.03 \pm 0.08$ & $9.70-10.60$ \\
\hline Ash & $0.68 \pm 0.01$ & $0.73 \pm 0.04$ & $0.05-0.06$ \\
\hline Crude fat & $0.15 \pm 0.01$ & $0.01 \pm 0.00$ & 0.03 \\
\hline $\begin{array}{l}\text { Carbohydrate } \\
\text { by difference }\end{array}$ & $0.74 \pm 0.01$ & $0.75 \pm 0.04$ & $0.40-0.90$ \\
\hline Reference & This study & {$[14]$} & {$[15]$} \\
\hline
\end{tabular}




\subsection{Effect of gelatin and carrageenan concentrations on the pudding's physical and sensorial properties}

\subsubsection{Colour}

$L^{*}, a^{*}$ and $b^{*}$ values of albumen puddings were significantly different from the commercial pudding, control sample (data not shown). $\Delta E^{*}$ which indicated the difference in colour between albumen pudding and control sample was shown in Table 2. The albumen pudding form $2 \%(\mathrm{w} / \mathrm{v})$ gelatin and $0.3 \%(\mathrm{w} / \mathrm{v})$ carrageenan had the lowest $\Delta E^{*}(5.05 \pm 0.11)$ which was not significant different form $2 \%(\mathrm{w} / \mathrm{v})$ gelatin and $0.5 \%$ $(\mathrm{w} / \mathrm{v})$ carrageenan $(5.51 \pm 0.31)$. The highest $\Delta E^{*}$ was found at $6 \%(\mathrm{w} / \mathrm{v})$ gelatin and $0.5 \%$ and $0.7 \%(\mathrm{w} / \mathrm{v})$ carrageenan which was $8.34 \pm 0.80$ and $8.22 \pm 0.44$, respectively.

Gelatin and carrageenan concentrations affected the $\Delta E^{*}$. Increase in the concentrations, the higher $\Delta E^{*}$ was observed. This might due to the fact that both of gelatin and carrageenan are white especially carrageenan can increase $L^{*}$ and decrease $a^{*}$ and $b^{*}$ resulting in higher $\Delta E^{*}[16]$.

Table 2. Colour difference ( $\left.\Delta E^{*}\right)$ of albumen pudding produced from various gelatin and carrageenan levels.

\begin{tabular}{|c|c|c|}
\hline $\begin{array}{c}\text { Gelatin } \\
(\mathbf{\%} \text { w/v })\end{array}$ & $\begin{array}{c}\text { Carrageenan } \\
(\mathbf{\%} \text { w/v })\end{array}$ & $\Delta \boldsymbol{E}^{*}$ \\
\hline \multirow{3}{*}{2} & 0.3 & $5.05 \pm 0.11^{\mathrm{a}}$ \\
\cline { 2 - 3 } & 0.5 & $5.51 \pm 0.31^{\mathrm{ab}}$ \\
\cline { 2 - 3 } & 0.7 & $6.13 \pm 0.24^{\mathrm{bc}}$ \\
\hline \multirow{3}{*}{4} & 0.3 & $5.95 \pm 0.18^{\mathrm{b}}$ \\
\cline { 2 - 3 } & 0.5 & $6.69 \pm 0.41^{\mathrm{cd}}$ \\
\cline { 2 - 3 } & 0.7 & $7.17 \pm 0.32^{\mathrm{d}}$ \\
\hline \multirow{3}{*}{6} & 0.3 & $6.92 \pm 0.10^{\mathrm{d}}$ \\
\cline { 2 - 3 } & 0.5 & $8.34 \pm 0.80^{\mathrm{e}}$ \\
\cline { 2 - 3 } & 0.7 & $8.22 \pm 0.44^{\mathrm{e}}$ \\
\hline
\end{tabular}

\subsubsection{Texture profile}

Textural properties of product are major importance to consumer. Hardness is defined as maximum force required to compress the sample. Springiness, ability of the sample to recover its original form after deforming force was removed, Cohesiveness, extent to which the sample could be deformed prior to rupture and Gumminess is defined as the product of hardness and cohesiveness. It is a characteristic of semisolid foods with a low degree of hardness and high degree of cohesiveness [17].

The textural profile of albumen pudding with various gelatin and carrageenan concentration was shown in Table 3. Albumen puddings from $4 \%(\mathrm{w} / \mathrm{v})$ gelatin with $0.5 \%$ and $0.7 \%(\mathrm{w} / \mathrm{v})$ carrageenan and those from $6 \%$ $(\mathrm{w} / \mathrm{v})$ gelatin with $0.5 \%$ and $0.7 \%(\mathrm{w} / \mathrm{v})$ carrageenan contributed a similar hardness to the control sample, 551-638 g compared to $582 \mathrm{~g}$, respectively. However, significantly difference was not found in springiness. This implied that an increase in gelation and carrageenan concentration did not affect springiness of albumen pudding. Moreover, springiness of albumen puddings, ranged from 0.50 to $0.64 \mathrm{~mm}$, was not significant different from that of control which was $0.57 \mathrm{~mm}$. Cohesiveness of albumen pudding, varied from 0.87 to 0.96 , was higher than that of the control which was 0.76

Though, an increase in gelatin and carrageenan concentrations did not affect cohesiveness of albumen pudding. Considering to gumminess, albumen pudding from $4 \%(\mathrm{w} / \mathrm{v})$ gelatin with $0.3 \%(\mathrm{w} / \mathrm{v})$ carrageenan was similar to the control, $447 \mathrm{~g}$ and $433 \mathrm{~g}$, respectively.

Results revealed that some textural properties were influenced by gelatin and carrageenan concentrations. Increase in gelatin concentration significantly increased hardness, cohesiveness and gumminess of albumen pudding ( $p$-value $<0.001$ ). While increase in carrageenan concentration significantly increased only hardness and gumminess $(p$-value $<0.001)$, but it did not affect cohesiveness of albumen pudding (data not shown). This might due to the fact that both of gelatin and carrageenan are food additives acting as gelling agents. Therefore, an increase in their concentrations provides food with a higher gel strength. Moreover, carrageenan is a one of polysaccharides. Carrageenan presents a random coiled structure in the solution at temperature above the melting point of the gel. In order to cool the solution to form a gel, a network of carrageenan polymers is built up and presents in a double helix structure, which be able to form junction points of the polymer chains. Further cooling leads to aggregation of these junction points to build a three-dimensional gel structure [16]. An increase in gel strength with increasing gelatin concentration was also reported [18].

Table 3. Texture profile of albumen pudding from various gelatin and carrageenan concentrations.

\begin{tabular}{|c|c|c|c|c|}
\hline $\begin{array}{c}\text { Gelatin } \\
(\% \mathbf{\%} / \mathbf{v})\end{array}$ & $\begin{array}{c}\text { Carrageenan } \\
(\mathbf{\%} / \mathbf{v})\end{array}$ & $\begin{array}{c}\text { Hardness } \\
(\mathbf{g})\end{array}$ & Cohesiveness & $\begin{array}{c}\text { Gumminess } \\
(\mathbf{g})\end{array}$ \\
\hline \multicolumn{2}{|c|}{ Control sample } & $582 \pm 131^{\mathrm{e}}$ & $0.76 \pm 0.09^{\mathrm{a}}$ & $433 \pm 55^{\mathrm{d}}$ \\
\hline \multirow{3}{*}{2} & 0.3 & $149 \pm 14^{\mathrm{ab}}$ & $0.87 \pm 0.07^{\mathrm{b}}$ & $130 \pm 11^{\mathrm{a}}$ \\
\cline { 2 - 5 } & 0.5 & $133 \pm 19^{\mathrm{a}}$ & $0.89 \pm 0.06^{\mathrm{b}}$ & $118 \pm 14^{\mathrm{a}}$ \\
\cline { 2 - 5 } & 0.7 & $238 \pm 18^{\mathrm{b}}$ & $0.90 \pm 0.02^{\mathrm{b}}$ & $213 \pm 12^{\mathrm{b}}$ \\
\hline \multirow{3}{*}{4} & 0.3 & $470 \pm 18^{\mathrm{d}}$ & $0.95 \pm 0.01^{\mathrm{b}}$ & $447 \pm 18^{\mathrm{de}}$ \\
\cline { 2 - 5 } & 0.5 & $551 \pm 73^{\mathrm{de}}$ & $0.95 \pm 0.03^{\mathrm{b}}$ & $508 \pm 64^{\mathrm{ef}}$ \\
\cline { 2 - 5 } & 0.7 & $638 \pm 27^{\mathrm{e}}$ & $0.94 \pm 0.01^{\mathrm{b}}$ & $597 \pm 20^{\mathrm{g}}$ \\
\hline \multirow{3}{*}{6} & 0.3 & $336 \pm 14^{\mathrm{c}}$ & $0.96 \pm 0.0^{\mathrm{b}}$ & $321 \pm 11^{\mathrm{c}}$ \\
\cline { 2 - 5 } & 0.5 & $597 \pm 32^{\mathrm{e}}$ & $0.95 \pm 0.01^{\mathrm{b}}$ & $568 \pm 33^{\mathrm{fg}}$ \\
\cline { 2 - 5 } & 0.7 & $589 \pm 64^{\mathrm{e}}$ & $0.95 \pm 0.0^{1 \mathrm{~b}}$ & $558 \pm 63^{\mathrm{fg}}$ \\
\hline
\end{tabular}

\subsubsection{Syneresis}

As shown in Fig. 1, Syneresis of albumen puddings increased during storage at $4^{\circ} \mathrm{C}$. A similar trend was observed in the control sample. Increasing syneresis during storage time could resulted from a closer arrangement of carrageenan gel structure, consequently resulting in and a higher amount of water expelled from a gel structure [19]. However, syneresis of the albumen puddings was much lower than that of the control. It ranged from $0.68-4.18 \%, 1.99-8.33 \%, 2.81-11.86 \%$ and $3.46-14.25 \%$ at $1,3,5$ and 7 day storage compared to the syneresis of control sample, which was $21.52 \%, 30.32 \%$, $31.63 \%$ and $31.97 \%$, respectively. Results also showed that an increase in gelatin and carrageenan concentrations decreased the degree of syneresis. These results were in 
accordance with Langendorff et al. [20] and Stanley [21] who revealed that a higher concentration of gelling agent causes a higher amount of double helix structure and also strengthen a gel structure that could preserve more water into the gel network, therefore less syneresis.

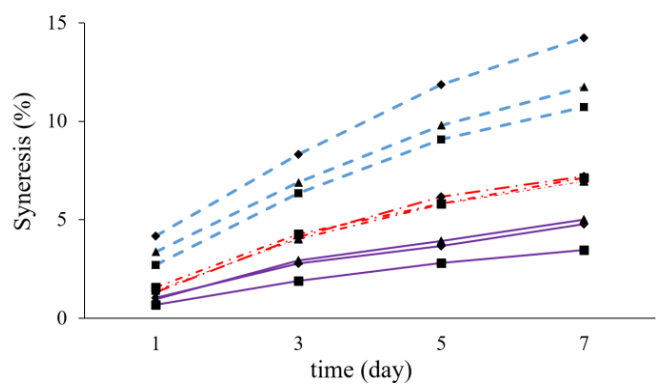

Fig. 1. Syneresis (\%) of albumen pudding from different concentrations of gelatin (dash line, 2\%; dash-dotted line, $4 \%$ and solid line, $6 \%)$ and carrageenan $(\diamond, 0.3 \% ; \boldsymbol{\Delta}, 0.5 \%$ and 口, $0.7 \%$ ) during storage.

\subsubsection{Sensorial properties}

The sensory liking scores of albumen pudding and the control were shown in Fig. 2. Liking scores of albumen pudding were between 5.5 (slightly like) and 6.7 (moderately like) depending on the gelatin and carrageenan concentrations, while those of the control sample were 6.8-7.5 (moderately like). The colour and overall liking scores of albumen pudding were in the range of slightly like to moderately like while the rest were in the range of slightly like. Overall liking score was not different among different concentrations. However, albumen puddings had a lower overall liking score than the control, ranged from slightly like compared to moderately like, respectively.

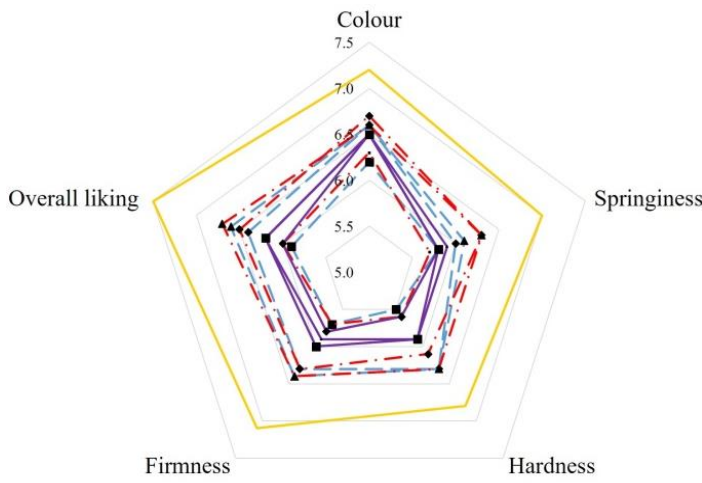

Fig. 2. Sensory liking score of albumen pudding from different concentrations of gelatin (dash line, 2\%; dash-dotted line, $4 \%$ and solid line, $6 \%)$ and carrageenan $(\bullet, 0.3 \% ; \boldsymbol{\Delta}, 0.5 \%$ and - $0.7 \%$ )

The results also showed that the entire liking scores of albumen pudding from $2 \%(\mathrm{w} / \mathrm{v})$ gelatin with $0.3 \%$ and $0.5 \%(\mathrm{w} / \mathrm{v})$ carrageenan and that from $4 \%(\mathrm{w} / \mathrm{v})$ gelatin with $0.3 \%$ and $0.5 \% \quad(\mathrm{w} / \mathrm{v})$ carrageenan, excluding overall liking, were not significantly different from those of control.

\subsection{Analysis of response surface}

Experimental modeling results for syneresis and sensorial properties are shown in Table $4 . \mathrm{R}^{2}$ of syneresis, liking scores of springiness, hardness, firmness and overall linking was $0.932,0.821,0.956,0.854$ and 0.864 , respectively. However, the model did not exhibit significantly model p-value for colour liking score.

Table 4. Predictive model and its regression coefficient.

\begin{tabular}{|l|l|c|}
\hline \multicolumn{1}{|c|}{ Response } & \multicolumn{1}{|c|}{ Predictive Model } & $\mathbf{R}^{\mathbf{2}}$ \\
\hline Syneresis & $17.7981-1.954 \mathrm{X}-4.1123 \mathrm{Y}$ & 0.932 \\
\hline Springiness & $\begin{array}{l}4.7663+0.2521 \mathrm{X}+4.9167 \mathrm{Y}- \\
0.0479 \mathrm{X}^{2}+0.1875 \mathrm{XY}-6.3542 \mathrm{Y}^{2}\end{array}$ & 0.821 \\
& $5.6389-0.2318 \mathrm{X}+5.4792 \mathrm{Y}-$ & 0.956 \\
& $0.0208 \mathrm{X}^{2}+0.6719 \mathrm{XY}-8.9583 \mathrm{Y}^{2}$ & \\
\hline Hardness & $5.7465-0.0443 \mathrm{X}+3.8958 \mathrm{Y}-$ & 0.854 \\
& $0.0323 \mathrm{X}^{2}+0.4844 \mathrm{XY}-6.6667 \mathrm{Y}^{2}$ & \\
\hline Overall & $5.3378+0.063 \mathrm{X}+5.5625 \mathrm{Y}-$ & 0.864 \\
liking & $0.0427 \mathrm{X}^{2}+0.4531 \mathrm{XY}-8.0208 \mathrm{Y}^{2}$ & \\
\hline
\end{tabular}

$\mathrm{X}=$ gelatin concentration, $\mathrm{Y}=$ carrageenan concentration

Based on regression equations, response surface plots were constructed to interpret the interactive effect of gelatin and carrageenan concentrations on colour and sensorial properties (Fig. 3.). It was found that an increase in the concentration improved a syneresis (Fig. 3a) but lowered sensorial liking scores (Fig. 3b-3e) including hardness, firmness and overall liking of albumen pudding. The findings were in accordance with textural properties. For instance, an increase in gelatin and carrageenan concentration increased hardness of the pudding (Table 3) resulting in lowering hardness liking score (Fig. 3c). (a)



(c)

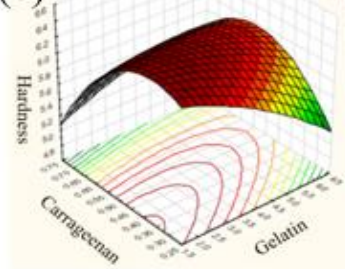

(b)

(d)

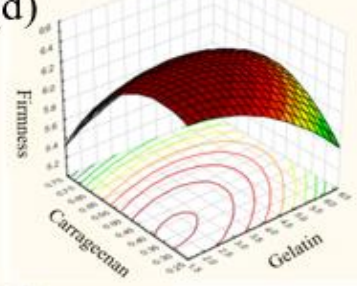

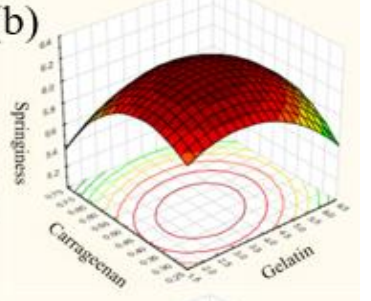

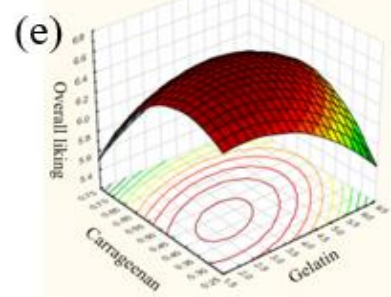

Fig. 3. Surface plot showing interaction effect of gelatin and carrageenan on syneresis (a), sensory liking scores on springiness (b), hardness (c), firmness (d) and overall liking (e) of albumen pudding. 
Corresponding contour plot was plotted and shown in Fig. 4. The contour plot showed that the optimum concentration of gelatin and carrageenan for albumen pudding production was $1.5-5.6 \%(\mathrm{w} / \mathrm{v})$ and $0.25-061 \%$ $(\mathrm{w} / \mathrm{v})$, respectively. According to these concentration, albumen pudding contributed less than $5 \%$ syneresis and liking scores of springiness, hardness, firmness and overall liking were not less than 6 (slightly like).

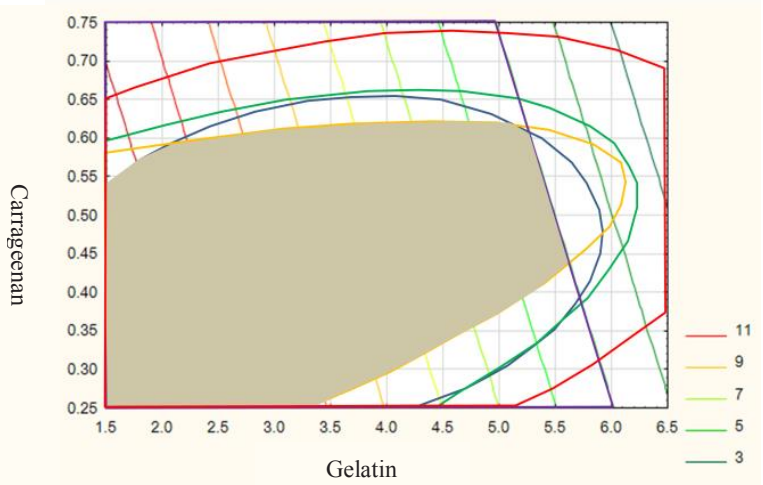

Fig. 4. Contour plot of the effect of gelatin and carrageenan concentrations on syneresis and sensorial properties.

\section{Conclusion}

Chicken albumen pudding was developed by application and optimization of gelatin and carrageenan using response surface methodology (RSM). Concentrations of gelatin and carrageenan affected the albumen pudding properties. $\mathrm{R}^{2}$ of syneresis, liking scores of springiness, hardness, firmness and overall linking were $0.932,0.821$, $0.956,0.854$ and 0.864 , respectively. An increase in concentrations lowered syneresis and sensorial properties. The optimum concentrations were $1.5-5.6 \%(\mathrm{w} / \mathrm{v})$ for gelatin and $0.25-061 \%(\mathrm{w} / \mathrm{v})$ for carrageenan. This work demonstrated that egg albumen can be utilized in a protein-rich pudding production, which could be a new food choice for consumers.

This work was financially supported by King Mongkut's University of Technology North Bangkok, Thailand. Authors would like to thank Miss Phornpimon Jainual for her kindly support.

\section{References}

1. A.A. Karim, G.A. Sulebele, M.E. Azhar, C.Y. Ping, Food Chem. 66, 159 (1999)
2. T. Cai, K.C. Chang, J Agric Food Chem. 47, 720 (1999)

3. R. Wang, X. Jin, S. Sue, Y. Lu, S. Guo, Food Hydrocoll. 97, 105230 (2019)

4. S. Eadmusik, P. Puwastien, A. Nitithamyong, KKU Res J. 18, 371 (2013)

5. H. Zhang, L. Yang, Y. Tu, N. Wu, Y. Jiang, M. Xu, J Food Process Eng. 42, e13071 (2019)

6. G. Wang, T. Wang, J Food Sci. 74, C147 (2009)

7. S.A. Mehdizadeh, S. Minaei, M.A.K. Torshizi, E. Mohajerani, J Food Sci Technol. 52, 4414 (2015)

8. H.G. Masure, A.G.B. Wouters, E. Fierens, J.A. Delcour, Food Hydrocoll. 95, 406 (2019)

9. L.A. Gogo, K.O. Gogo, P.L. Shalo, S.M. Mahungu, Int J Food Stud. 1, 52 (2012)

10. T. Amatayakul, F. Sherkat, N.P. Shah, Int J Dairy Technol. 59, 216 (2006)

11. S.P. Huertas, K. Terpilowki, M.T. Mleko, K. Nishinari, S. Mleko, Food Hydrocoll. 96, 224 (2019)

12. Y.N. Chang, J.C. Huang, C.C. Lee, I.L. Shih, Y.M. Tzeng, Enzyme Microb Tech. 30, 889 (2002)

13. AOAC. Official method of analysis (Assosiation of Official Analytical Chemists, Washington DC, 2000)

14. W. Chaiyasit, R.G. Brannan, D. Chareonsuk, W. Chanasattru, Rev Bras Cienc Avic. 21, 1 (2019)

15. W.J. Stadelman, O.J. Cotterill, Egg science and technology (Food Produce Press, New York, 1995)

16. L. Piculell, Food polysaccharides and their application (Marcel Dekker Inc., New York, 1995)

17. M.V. Chandra, B.A. Shamasundar, Int J Food Prop. 18, 572 (2015)

18. J. Pye, Gelatin and applications (Food Science and Technology Association of Thailand, 1997)

19. T.R. Thrimawithana, S. Young, D.E. Dunstan, B.G. Alany, Carbohydr Polym. 82, 69 (2010)

20. V. Langendorff, G. Cuvelier, C. Michon, B. Launay, A. Parher, C.G.D. Kruif, Food Hydrocoll. 14, 273 (2000)

21. N.F. Stanley, Food polysaccharides and their application (Marcel Dekker Inc., New York, 1995) 